\title{
Latent Membrane Protein-1 Protein Induction toward Vascular Endothelial Growth Factor Expression in the Development of Nasopharyngeal Carcinoma
}

\author{
Jessy Chrestella ${ }^{1}$, Farhat Farhat ${ }^{2 *}$, Elvita Rahmi Daulay ${ }^{3}$, Sheba Tarigan $^{2}$, Raudah Putri Syari $^{4}$ \\ ${ }^{1}$ Department of Pathology, Faculty of Medicine, Universitas Sumatera Utara, Medan, North Sumatera, Indonesia; ${ }^{2}$ Department \\ of Otorhinolaryngology-Head and Neck Surgery, Faculty of Medicine, Universitas Sumatera Utara, Medan, North Sumatera, \\ Indonesia; ${ }^{3}$ Department of Radiology, Faculty of Medicine, Universitas Sumatera Utara, Medan, North Sumatera, Indonesia; \\ ${ }^{4}$ Faculty of Medicine, Universitas Sumatera Utara, Medan, North Sumatera, Indonesia
}

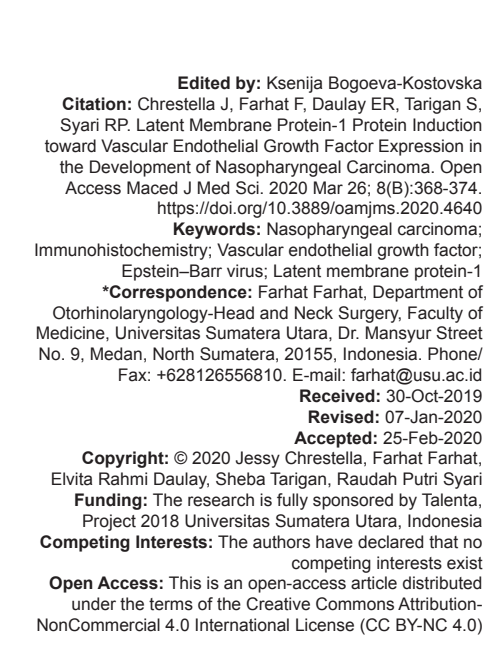

\begin{abstract}
BACKGROUND: Nasopharyngeal carcinoma (NPC) is associated with Epstein-Barr virus infection as the main factor. Latent membrane protein (LMP)-1 protein and vascular endothelial growth factor (VEGF) have been suggested as the prognostic biomarker for NPC.

AIM: This study is conducted to analyze the overexpression of LMP-1 protein and VEGF and the combination of these two in NPC patients. The role of LMP-1 protein in the induction of VEGF is identified by analyzing the association between these two proteins.

METHODS: A cross-sectional design study is conducted at Adam Malik General Hospital. Formalin-fixed, paraffinembedded sections from the NPC tissue samples are submitted for immunohistochemistry staining. Fisher's exact test is used to analyze variables relation.

RESULTS: Among 56 samples, there was a significant correlation between LMP-1 protein overexpression with histopathological type and clinical staging, and VEGF overexpression with lymph node enlargement and clinica staging $(p<0.05)$. There was no significant correlation between LMP-1 protein with VEGF in NPC patients $(p>0.05)$ CONCLUSION: Increased expressions of LMP-1 protein, VEGF, and a combination of LMP-1 protein and VEGF are noted in correlation with increasing the clinical stages. In contrast to the previously suggested hypotheses, the correlation between these two proteins is not significant in the present study. It could happen due to the different associations of each protein overexpression toward the clinical parameter. However, these two proteins could be used in evaluating the prognosis and providing a targeted therapy to NPC.
\end{abstract}

\section{Introduction}

Nasopharyngeal carcinoma (NPC) is a rare disease with 85.000 cases and 50.000 death reported worldwide. It is an uncommon disease in the west but endemic in South China and Southeast Asia [1], [2]. GLOBOCAN 2012 showed that the incidence of NPC in Indonesiabased onage-standardized ratewas 8.3/100.000 in male and 3.0/100.000 in female [3]. It is also known as a disease with a distinct geographical distribution. NPC arises from the epithelium of nasopharynx and the most location of the disease is in the fossa Rosenmüller [4].

Factors involved in progression of NPC are multifactorial including genetic, environment exposure, diet, geographic, and Epstein-Barr virus (EBV) infection. EBV infection is thought to be the main factor for pathogenesis of NPC [2], [4]. EBV latent infection express the EBV nuclear antigen, latent membrane protein (LMP)-1, LMP-2, EBV-encoded small RNAs, and miRNAs derived from BamHI-A rightward transcript [5].
In NPC cases, LMP-1 protein is expressed up to $65 \%$ among the cases. It has a great influence in gene expression and contribute to EBV-mediated tumorigenesis [2]. LMP-1 protein is known to activate several signaling pathways including NF-KB signaling pathway, MAPK pathways (Erk1/2, JNK, P38), STAT3, the PI3-kinase/Akt, and many others which contribute to the development of NPC [6], [7]. LMP-1 protein is involved in the promotion of cell motility, invasion, proliferation, lymph-angiogenesis, and epithelial mesenchyme transition [8].

Vascular endothelial growth factor (VEGF) is known as the most common growth factor responsible for tumorigenesis. It is involved in angiogenesis which is necessary in tumor growth by enhancing migration and proliferation of endothelium [9]. It is also known to be correlated with tumor stage, nodal involvement, and metastasis [10]. VEGF is known to be induced by LMP-1 protein along with the expression cyclooxygenase-2, epidermal growth factor receptor (EGFR), and other biomarkers that enhance cell 
survival and proliferation [11]. LMP-1 protein and VEGF have been recognized as prognostic biomarkers for NPC. This study is conducted to identify the correlation between these two biomarkers and the implication of their expression on the clinicopathologic parameters of NPC patients. This will shed a light on the prognostic value of these proteins and may provide an insight to a targeted therapy for this aggressive carcinoma.

\section{Methods}

\section{Patients and samples}

The study was performed at Adam Malik General Hospital. Archives from the period 2016 to 2017 were included in the study. Fifty-six paraffin blocks of previously biopsied and diagnosed NPCs were collected. The included samples were selected from patients with no other associated malignancies and with no prior chemo or radiotherapy. Immunohistochemistry staining is performed.

The variables of the study were LMP-1 protein expression, VEGF expression, primary tumor size ( $T$ ), the presence of distant metastasis (M), lymph node enlargement $(\mathrm{N})$, and clinical staging. We used the American Joint Committee on Cancer (AJCC) staging system 2010 to determine the cancer staging of the patients. Computer tomography scan with contrast was used to evaluate the primary tumor size and lymph node enlargement based on AJCC 2010. The histopathological type of cancer was determined based on the WHO criteria. The expression of LMP-1 protein and VEGF was evaluated by immunohistochemistry staining. The study has been approved by the Health Research Ethical Committee, Medical Faculty of Universitas Sumatera Utara/Adam Malik General Hospital, and the methods did not contradicted with the Declaration of Helsinki.

\section{Immunohistochemistry staining}

The paraffin blocks were cut into sections, deparaffinized and then rehydrated. Antigen retrieval performed in the Dako Epitope Retrieval and heated at $980^{\circ} \mathrm{C}$ for $15 \mathrm{~min}$. The specimens were incubated with the primary antibody, anti-LMP-1 antibody, and anti-VEGF antibody. The tissues then were evaluated by two pathologists to identify the overexpression of LMP-1 protein and VEGF without knowing the clinical parameters of the patients.

\section{Statistical analysis}

All of the data gathered from the study were analyzed using the Statistical Package for the Social
Sciences $^{\mathrm{TM}}$ 23.0. We analyzed the correlation between the overexpression of LMP-1 protein, VEGF, and both of them with primary tumor, lymph node metastasis, and clinical staging evaluated using Fisher's exact test. The correlation between LMP-1 protein and VEGF in NPC patients was also evaluated using Fisher's exact test. The correlation is found if $p<0.05$.

\section{Results}

The total samples in this study were 56 samples of paraffin blocks of NPC biopsy. Table 1 shows the demographic data of the samples based on distribution of age, sex, and WHO classification. The distribution of NPC patients based on age, sex, and WHO classification is shown in Table 1.

Table 1: Demographic distribution based on age, sex, and WHO classification

\begin{tabular}{lll}
\hline Characteristic & $\mathbf{n}$ & $\%$ \\
\hline Age (years) & 1 & \\
$\leq 20$ & 10 & 1.8 \\
$21-40$ & 33 & 17.9 \\
$41-60$ & 12 & 58.9 \\
$>60$ & & 21.4 \\
Sex & 43 & 76.8 \\
$\quad$ Male & 13 & 23.2 \\
Female & & \\
WHO classification & 6 & 10.7 \\
WHO Type I & 42 & 75.0 \\
WHO Type II & 8 & 14.3 \\
WHO Type III & \\
\hline
\end{tabular}

We found 42 samples $(75.0 \%)$ were nonkeratinizing squamous cell carcinoma (WHO Type II) based on histopathological type. This is followed by undifferentiated carcinoma (WHO Type III) with eight samples (14.3\%) and the least was keratinizing squamous cell carcinoma (WHO Type I) with six samples $(10.7 \%)$

The distribution of LMP-1 and VEGF expression based on clinical characteristics is shown in Table 2. LMP-1 protein was overexpressed in 47 samples (83.9\%) and negative in nine. The overexpression of LMP-1 was highest in samples with WHO Type II with 40 samples $(85.1 \%)$ and then followed by the WHO Type III with six samples $(11.1 \%)$. The least occurrence was in the WHO Type I with just one sample $(2.1 \%)$. The association of LMP-1 protein expression with histopathological type was found significant with $p<0.05$.

This study showed that the overexpression of LMP-1 protein was the highest in the primary tumor T3 and T4 with 16 samples (34.0\%) and followed with slight difference by primary tumor T2 with 12 samples (25.5\%). The least was T1 with 3 samples (6.4\%).

The overexpression of LMP-1 protein was highest in NPC patients with N3, which were 20 samples $(42.6 \%)$. The second highest occurrence of LMP-1 protein overexpression was found in N2 with 15 samples (31.9\%). The lowest was found in N1 and N0 with seven samples (14.9\%) and five samples (10.6\%), 
Table 2: Expression of LMP-1 protein and VEGF according the to clinical characteristics of NPC

\begin{tabular}{|c|c|c|c|c|c|c|c|c|}
\hline \multirow[t]{2}{*}{ Characteristic } & \multicolumn{8}{|c|}{ LMP-1 protein and VEGF expression (\%) } \\
\hline & $\begin{array}{l}\text { Over expression of combination } \\
\text { of LMP-1 protein and VEGF }\end{array}$ & $p$-value & $\begin{array}{l}\text { Over expression of } \\
\text { LMP-1 protein }\end{array}$ & $p$-value & $\begin{array}{l}\text { Over expression of } \\
\text { VEGF }\end{array}$ & $\mathrm{p}$-value & $\begin{array}{l}\text { Negative over } \\
\text { expression }\end{array}$ & $p$-value \\
\hline WHO classification & & $<0.001^{*}$ & & $<0.001^{*}$ & & $0.367^{*}$ & & $0.107^{*}$ \\
\hline WHO type I & $1(2.3)$ & & $1(2.1)$ & & $5(9.8)$ & & $0(0.0)$ & \\
\hline WHO type II & $37(86.0)$ & & $40(85.1)$ & & $39(76.5)$ & & $1(100.0)$ & \\
\hline WHO type III & $5(11.6)$ & & $6(11.1)$ & & $7(13.7)$ & & $0(0.0)$ & \\
\hline Primary tumor size & & $0.019^{*}$ & & $0.091^{*}$ & & $0.124^{*}$ & & $0.089^{*}$ \\
\hline T1 & $3(7.0)$ & & $3(6.4)$ & & $4(7.8)$ & & $1(100.0)$ & \\
\hline T2 & $9(20.9)$ & & $12(25.5)$ & & $12(23.5)$ & & $0(0.0)$ & \\
\hline T3 & $15(34.9)$ & & $16(34.0)$ & & $19(37.3)$ & & $0(0.0)$ & \\
\hline T4 & $16(37.2)$ & & $16(34.0)$ & & $16(31.4)$ & & $0(0.0)$ & \\
\hline Lymph node & & $0.136^{\star}$ & & $0.656^{*}$ & & $0.040^{*}$ & & $0.125^{\star}$ \\
\hline No & $4(9.3)$ & & $5(10.6)$ & & $5(9.8)$ & & $1(100.0)$ & \\
\hline N1 & $5(11.6)$ & & $7(14.9)$ & & $7(13.7)$ & & $0(0.0)$ & \\
\hline N2 & $15(34.9)$ & & $15(31.9)$ & & $17(33.3)$ & & $0(0.0)$ & \\
\hline N3 & $19(44.2)$ & & $20(42.6)$ & & $22(43.1)$ & & $0(0.0)$ & \\
\hline Distant metastasis & & $0.058^{\star}$ & & $0.272^{*}$ & & $0.161^{*}$ & & $0.446^{*}$ \\
\hline MO & $16(37.2)$ & & $19(40.4)$ & & $21(41.2)$ & & $1(0.0)$ & \\
\hline M1 & $27(62.8)$ & & $28(59.6)$ & & $30(58.8)$ & & $0(0.0)$ & \\
\hline Stage grouping & & $0.001^{\star}$ & & $0.017^{*}$ & & $0.008^{*}$ & & $0.018^{*}$ \\
\hline I & $0(0.0)$ & & $0(0.0)$ & & $0(0.0)$ & & $1(100.0)$ & \\
\hline II & $1(2.3)$ & & $3(6.4)$ & & $4(7.8)$ & & $0(0.0)$ & \\
\hline III & $15(34.9)$ & & $16(34.0)$ & & $17(33.3)$ & & $0(0.0)$ & \\
\hline IV & $27(62.8)$ & & $28(59.6)$ & & $30(58.8)$ & & $0(0.0)$ & \\
\hline
\end{tabular}

respectively. The overexpression of LMP-1 protein in patients with the presence of distant metastasis was found in high numbers of sample than the absence of it with 28 samples (59.6\%) and 19 samples (40.4\%), respectively.

Table 3: LMP-1 protein and VEGF expression in NPC

\begin{tabular}{lll}
\hline & \multicolumn{2}{l}{ VEGF expression (\%) } \\
\cline { 2 - 3 } & Positive & Negative \\
\hline LMP-1 protein & & \\
expression & $43(84.3)$ & $4(80.0)$ \\
Positive & $8(15.7)$ & $1(20.0)$ \\
Negative & & \\
\hline$p=1.000^{*}$. ${ }^{*}$ Fisher's exact test. LMP-1: Latent membrane protein-1, VEGF: Vascular endothelial growth \\
factor, NPC: Nasopharyngeal carcinoma.
\end{tabular}

As regards staging, there was no overexpression of LMP-1 protein in Stage I. The highest occurrence of LMP-1 protein overexpression was found in Stage IV with 28 samples (59.6\%) and then followed by Stage III with 16 samples (34.0\%). LMP-1 protein overexpression was found in Stage II with three samples $(6.4 \%)$. There was significant association of histopathological type and clinical staging with LMP-1 protein overexpression with $p<0.05$. There was no significant association of primary tumor size, lymph node enlargement, and distant metastasis with LMP-1 protein overexpression.

VEGF was overexpressed in 51 samples $(91.1 \%)$ and negative in five. The overexpression of VEGF was highest in samples with non-keratinizing squamous cell carcinoma with 39 samples (76.5\%). The second highest was in undifferentiated carcinoma with seven samples (13.7\%). The least was in keratinizing squamous cell carcinoma type with five samples (9.8\%).

Based on primary tumor size, VEGF overexpression was the highest in T3 with 19 samples (37.3\%). It then followed by T4 with 16 samples (31.4\%), T2 with 12 samples $(23.5 \%)$, and the least was T1 with four samples $(7.8 \%)$.

VEGF overexpression in NPC patients in relation to the lymph node enlargement was found in N3 with 22 samples (43.1\%). The second highest was found in N2 with 17 samples (33.3\%). Then, it followed by $\mathrm{N} 1$ and $\mathrm{N} 0$ with seven samples (13.7\%) and five samples $(9.8 \%)$, respectively. There were 30 samples $(58.8 \%)$ with the presence of distant metastasis in NPC patients with the overexpression of VEGF. It was higher than the patients with no distant metastasis which accounted for 21 samples (41.2\%).

VEGF overexpression was highest in clinical Stage IV based on the staging group with 30 samples $(58.8 \%)$. It then followed by Stage III with 17 samples (33.3\%) and Stage II with four samples (7.8\%). There was no found VEGF overexpression in clinical Stage I NPC patients. There was no significant correlation between histopathological type, primary tumor size, and the presence of distant metastasis with VEGF overexpression with $p>0.05$. However, significant correlation was found between VEGF overexpression with lymph node enlargement and clinical staging with $\mathrm{p}<0.05$.

The dual expression of LMP-1 protein and VEGF overexpression was found in 43 samples $(76.8 \%)$. Based on histopathological type, overexpression of both proteins was found highest in non-keratinizing squamous cell carcinoma with 37 samples (86.0\%). This was followed by keratinizing squamous cell carcinoma and undifferentiated carcinoma with five samples (11.6\%) and one sample $(2.3 \%)$, respectively. A slight difference in LMP-1 expression was noticed in relation to the primary tumor size, T4 and T3 with 16 samples (37.2\%) and 15 samples (34.9\%), respectively. The least expression was noticed in T2 with nine samples $(20.9 \%)$ and T1 with three samples $(7.0 \%)$. As regard, the lymph node status, N3 was the most common for both LMP-1 protein and VEGF overexpression with 19 samples (44.2\%), then followed by N2, N1, and N0 with 15 samples (34.9\%), five samples (11.6\%), and four samples (9.3\%), respectively. The overexpression of both LMP-1 protein and VEGF was found highest in the presence of distant metastasis with 27 samples (62.8\%), and higher than the patients without distant metastasis with 16 samples (37.2\%). Clinical Stage IV was the highest occurrence 
for both of LMP-1 protein and VEGF overexpression with 27 samples (62.8\%). Stage III and Stage II accounted in 15 samples $(34.9 \%)$ and one sample (2.3\%), respectively, for the overexpression of LMP-1 protein and VEGF combination. There was no overexpression in the combination of both proteins in Stage I. There was significant association of histopathological type, primary tumor size, and clinical staging with the overexpression of the combination of LMP-1 protein and VEGF with $p<0.05$. Fisher's exact test in Table 3 showed there was no significant association between LMP-1 protein and VEGF in NPC patients ( $p>0.05)$.

\section{Discussion}

LMP-1 protein is an oncoprotein expressed by EBV latent infection [5], [12]. It activates several signaling pathway including $\mathrm{NF}-\mathrm{KB}$, activator protein 1 (AP-1), p38 MAPK, Janus-activated kinase/signal transducers, and activators of transcription pathways. This role of LMP-1 protein is associated with the tumorgenesis as well as metastasis and invasiveness of the cancer cells. Through the activation of NF-KB and AP-1, LMP-1 protein is thought to activate tumor growth factor- $\alpha$ (TGF- $\alpha$ ) lead to EGFR activation and thus enhance proliferation of cells [13], [14]. It also alters function of tumor suppressor genes including p53 by MAPK pathway and RASSF1A, the most common inactivated tumor suppressor gene in NPC. LMP1 also plays a role in the down-regulation of $\mathrm{p} 16$. p16 plays a role in cell cycle checkpoint and activation of cyclin D1 which is an oncogene that plays a role in the development of cancer through stimulation of STAT3 and EGFR. LMP-1 protein can protect cells from apoptosis by activating NF-KB and STAT3 [14], [15], [16]. The study by You et al. revealed the role of LMP-1 protein in upregulating nuclear accumulation of $\beta$-catenin which needed for Wnt signaling pathway. $\beta$-catenin regulates the expression of genes which responsible for cancer including overexpression of cyclin D1 and downregulation of RASSF1A in NPC [17].

Role of LMP-1 protein in invasiveness and metastasis was taken in several mechanisms. It promotes metastasis by upregulating matrix-metalloproteinases- 9 which degrades extracellular matrix protein and upregulates VEGF as a proangiogenic factor for cancer cells [18]. LMP-1 protein, by upregulating $\beta$-catenin, is involved in invasive and metastasis of cells through downregulating the cell adhesion [17]. Activation of JAK/STAT and MAPK/ERK by LMP-1 protein also took parts in metastasis by altering cell-cell adhesion, matrix extracellular degradation, and enhanced motility and migration of NPC cells [19]. Downregulation of E-cadherin and overexpression of twist and snail, which induced by LMP-1 protein, alter the integrity of NPC cells. This process then lead to invasive and metastasis of cells [14]. LMP-1 protein induces hypoxia-inducible factor-1 $\alpha$ which also increased cells motility lead to potentiation for invasiveness [20].

Our study revealed overexpression of LMP-1 protein in $83.9 \%$ of cases. There was association of histopathological type and clinical staging with LMP-1 protein overexpression in NPC patients. It supported by Wang et al. in their study which resulted 38 of 61 (62.3\%) LMP-1 protein positive cases. Their study also revealed the significant association of LMP-1 protein expression with TNM stage/clinical staging [21]. The study by $\mathrm{Li}$ et al. showed the expression of LMP-1 protein in 24 of $56(43 \%)$ NPC patients. However, there was not found any significant association of LMP-1 protein expression with tumor value, $\mathrm{N}$ stage, and clinical stage in their study.

There were 36 of $40(90 \%)$ patients which showed LMP-overexpression in study conducted by Borthakur et al. The association of histopathological type and the expression of LMP-1 protein was found in their study [22]. It was suggested that differentiation status of histopathological type associated with Wnt/ $\mathrm{B}$ catenin signaling pathway activation. The recent was most found in the non-keratinizing squamous cell carcinoma type. This supported the result of our study which showed that the high expression of LMP-1 protein was the highest in non-keratinizing squamous cell carcinoma [17].

The study by Rosales et al. showed just 10 of $25(40 \%)$ samples with positive LMP-1 protein expression and the significant association of older age and parapharyngeal space invasion with LMP-1 protein expression. They suggested that LMP-1 protein expression may be associate with poorer prognosis in NPC patients [23]. Tabyaoui et al. in their study did not detect any overexpression of LMP-1 protein in NPC patients [24].

VEGF had others name such as vascular permeability factor or vascultropin. According to its name, it has mitogenic and angiogenic potentiation and allows the permeability of endothelial cells [25]. It is located on 6p21.3 chromosome and serves as the main growth stimulated factor in angiogenesis of tumor through migration and proliferation endothelial cells [9]. Its expression is regulated by several growth factors such as EGF, TGF- $\alpha$, TGF- $\beta$, IL-1 $\alpha$, IL-1 $\beta$, PGE2, IL-6, and IGF1 [26]. VEGF acts by binding to the receptor tyrosine kinase including VEGF receptor-1 (Flt-1) and VEGF receptor-2 (KDR/Flk-1) [27]. The binding of VEGF to its receptor promotes proliferation, survival, and motility of endothelial cells. The overexpression of VEGF has shown in most tumors, including NPC. It was known to have significant correlation with tumor stage, nodal involvement, and metastasis thus suggested as prognostic biomarker [10], [28]. It correlates with disease recurrences and poor prognosis of NPC [26]. 
Our study shows the overexpression of VEGF in 51 of $56(91.1 \%)$ samples. There is a significant correlation between VEGF overexpression with the lymph node status and clinical staging. These results are compatible with the study of Pan et al. resulted in VEGF overexpression in $66.7 \%$ of 111 NPC patients. They also revealed that patients with overexpression of VEGF had worse prognosis than without VEGF overexpression. VEGF overexpression was an independent factor of non-metastasis for overall survival, disease- free survival, loco-regional control, and distant metastasis-free survival [27]. Study by Kim et al. showed the association of VEGF overexpression with high clinical staging (III and IV vs. I and II) and high nodal stage (N2 and N3 vs. N0 and N1). Their study also revealed there was not association of VEGF overexpression with worse prognosis [10]. However, Dan et al. revealed from their study that positive VEGF expression was independent prognostic factor in NPC. The overexpression of VEGF was found with proportion $66.9 \%$ and was significantly associate with primary tumor, lymph node metastasis, and clinical stage [29].

$\mathrm{Li}$ et al. in their study showed the positive VEGF expression in 86 of 188 (45.7\%) NPC cases. The correlation of VEGF expression with clinical stage, recurrence, and distant metastasis was significant, but not with $\mathrm{T}$ stage and lymph node metastasis. The 5-year survival rate of the VEGF overexpression was lower than patients with low expression in NPC patients. Their study resulted in association of VEGF overexpression with poor prognosis [9]. Study by Kurnianda et al. showed that the patients with VEGF overexpression had shorter survival rate than lower VEGF expression but the difference was not significant. It showed the expression of VEGF in 30 patients, with high overexpression in 11 patients and low expression in 19 patients [25].

Other studies also revealed the overexpression of VEGF in NPC patients and the association of it with clinicopathology parameter and poor prognosis. Study by Xinhua et al. showed the overexpression of VEGF in 60 of $86(69.8 \%)$ NPC patients. Segawa et al. in their study revealed the overexpression of VEGF in 30 of $76(39.5 \%)$ NPC cases. There was no significant association of primary tumor size, lymph node enlargement, and clinical staging with VEGF overexpression. The survival rate of NPC patients with overexpression of VEGF was shorter than patients without it and suggested VEGF as predictive marker in recurrence and metastasis of NPC [28], [30].

It was known that the association of LMP-1 protein with VEGF that it acts as inducers of VEGF [31], [32]. VEGF is expressed by LMP-1 protein through the activation of JAK/STAT and MAPK/ ERK signaling pathway [19]. Promoter of VEGF has NF-KB and AP-1 sites which are the signaling pathway induced by LMP-1 protein. It provides the statement that VEGF upregulation may be the result of direct signaling by LMP-1 protein [13]. Our study resulted in there was association of combined LMP-1 protein and VEGF overexpression in NPC patients with the histopathological type, primary tumor size, and clinical staging. It came from the role of LMP-1 protein in differentiate histopathological type and promotes the metastasis and invasive of cancer cells along with VEGF. However, different from the known association of those two, we found that there was not significant association between LMP-1 protein and VEGF. We suggested it may be due to difference association of each with four clinicopathological parameter adjusted. Regardless of that, the combination of those two had relation with the clinicopathological of NPC patients, especially clinical stage. This result supports the role of LMP-1 protein and VEGF using as prognostic biomarker of NPC.

The majority of the cases in the study showed overexpression of LMP-1 and VEGF as well as dual reactivity to both markers. The overexpression of these was highest among non-squamous cell carcinoma cases, T3, N3, and Stage IV NPC.

\section{Conclusion}

There were significant association of LMP-1 protein overexpression with histopathological type and clinical staging, and VEGF overexpression with lymph node enlargement and clinical staging. There was a nonsignificant correlation between LMP-1 protein and VEGF overexpression. It is needed to do further research to identify the relation of LMP-1 protein and VEGF. More research is required to identify the correlation between the two markers. Furthermore, further work is needed to discover new targeted therapies for this aggressive carcinoma.

\section{Funding Sources}

The research is fully sponsored by Talenta Project 2018 Universitas Sumatera Utara. Sponsor has no involvement regarding the content of the article such as data collection, analysis, and interpretation or the decision to submit the manuscript for publication.

\section{References}

1. Mahdavifar N, Towhidi F, Makhsosi BR, Pakzad R, Moini A, Ahmadi $A$, et al. Incidence and mortality of nasopharynx cancer and its relationship with human development index in 
the world in 2012. World J Oncol. 2016;7(5-6):109. https://doi. org/10.14740/wjon980w

PMid:28983375

2. Zeng MS, Zeng YX. Pathogenesis and Etiology of Nasopharyngeal Carcinoma. Nasopharyngeal Cancer. Berlin, Germany: Springer; 2010. p. 9-25.

3. Wei KR, Zheng RS, Zhang SW, Liang ZH, Ou ZX, Chen WQ. Nasopharyngeal carcinoma incidence and mortality in China in 2010. Chin J Cancer. 2014;33(8):381.

PMid:25096544

4. Chua ML, Wee JT, Hui EP, Chan AT. Nasopharyngeal carcinoma. Lancet. 2016;387(10022):1012-24. https://doi.org/10.1016/ s0140-6736(15)00055-0

PMid:26321262

5. Huang S, Tsao S, Tsang C. Interplay of viral infection, host cell factors and tumor microenvironment in the pathogenesis of nasopharyngeal carcinoma. Cancers. 2018;10(4):106. https:// doi.org/10.3390/cancers10040106

PMid:29617291

6. Gourzones C, Busson P, Raab-Traub N. Epstein-barr Virus and the Pathogenesis of Nasopharyngeal Carcinomas. Nasopharyngeal Carcinoma. Berlin, Germany: Springer; 2013. p. 42-60. https://doi.org/10.1007/978-1-4614-5947-7_4

7. Tulalamba W, Janvilisri T. Nasopharyngeal carcinoma signaling pathway: An update on molecular biomarkers. Int J Cell Biol. 2012;2012:10. https://doi.org/10.1155/2012/594681

8. Yoshizaki T, Kondo S, Wakisaka N, Murono S, Endo K, Sugimoto $\mathrm{H}$, et al. Pathogenic role of epstein-barr virus latent membrane protein-1 in the development of nasopharyngeal carcinoma. Cancer Lett. 2013;337(1):1-7. https://doi. org/10.1016/j.canlet.2013.05.018

PMid:23689138

9. Li YH, Hu CF, Shao Q, Huang MY, Hou JH, Xie D, et al. Elevated expressions of survivin and VEGF protein are strong independent predictors of survival in advanced nasopharyngeal carcinoma. J TransI Med. 2008;6(1):1. https:// doi.org/10.1186/1479-5876-6-1

PMid:18171482

10. Kim TJ, Lee YS, Kang JH, Kim YS, Kang CS. Prognostic significance of expression of vegf and cox-2 in nasopharyngeal carcinoma and its association with expression of C-erbB2 and EGFR. J Surg Oncol. 2011;103(1):46-52. https://doi. org/10.1002/jso.21767

PMid:21031415

11. Yang G, Deng Q, Fan W, Zhang Z, Xu P, Tang S, et al. Cyclooxygenase-2 expression is positively associated with lymph node metastasis in nasopharyngeal carcinoma. PLoS One. 2017;12(3):e0173641. https://doi.org/10.1371/journal. pone. 0173641

PMid:28301518

12. Huang $D$, Song $S J, W u Z Z, W u ~ W$, Cui $X Y$, Chen JN et al. Epstein-barr virus-induced VEGF and GM-CSF drive nasopharyngeal carcinoma metastasis via recruitment and activation of macrophages. Cancer Res. 2017;77(13):3591-604. https://doi.org/10.1158/0008-5472.can-16-2706

PMid:28484077

13. Stevenson D, Charalambous C, Wilson JB. Epstein-barr virus latent membrane protein 1 (CAO) up-regulates VEGF and TGFa concomitant with hyperlasia, with subsequent up-regulation of p16 and MMP9. Cancer Res. 2005;65(19):8826-35. https://doi. org/10.1158/0008-5472.can-05-0591

14. Dawson CW, Laverick L, Morris MA, Tramoutanis G, Young LS Epstein-barr virus-encoded LMP-1 regulates epithelial cell motility and invasion via the ERK-MAPK pathway. J Virol. 2008;82(7):3654-64. https://doi.org/10.1128/jvi.01888-07

\section{PMid:18199641}

15. Xu Y, Shi Y, Yuan Q, Liu X, Yan B, Chen L, et al. Epstein-barr virus encoded LMP-1 regulates cyclin D1 promoter activity by nuclear EGFR and STAT3 in CNE1 cells. J Exp Clin Cancer Res. 2013;32(1):90. https://doi.org/10.1186/1756-9966-32-90 PMid:24499623

16. Zheng H, Li L, Hu D, Deng X, Cao Y. Role of epstein-barr virus encoded latent membrane protein 1 in the carcinogenesis of nasopharyngeal carcinoma. Cell Mol Immunol. 2007;4(3):185-96. PMid:17601372

17. You S, Zhang F, Meng F, Li H, Liu Q, Liang $\mathrm{Y}$, et al. EBVencoded LMP-1 increases nuclear $\beta$-catenin accumulation and its transcriptional activity in nasopharyngeal carcinoma. Tumor Biol. 2011;32(4):623-30. https://doi.org/10.1007/ s13277-011-0161-x

PMid:21336584

18. Chew MM, Gan SY, Khoo AS, Tan EL. Interleukins, laminin and epstein-barr virus latent membrane protein 1 (EBV LMP-1) promote metastatic phenotype in nasopharyngeal carcinoma. BMC Cancer. 2010;10(1):574. https://doi. org/10.1186/1471-2407-10-574

PMid:20964870

19. Wang Z, Luo F, Li L, Yang L, Hu D, Ma X, et al. STAT3 activation induced by epstein-barr virus latent membrane protein1 causes vascular endothelial growth factor expression and cellular invasiveness via JAK3 And ERK signaling. Eur J Cancer. 2010;46(16):2996-3006. https://doi.org/10.1016/j. ejca.2010.07.008

PMid:20709526

20. Aga M, Bentz GL, Raffa S, Torrisi MR, Kondo S, Wakisaka N, et al Exosomal HIF1a supports invasive potential of nasopharyngeal carcinoma-associated LMP-1-positive exosomes. Oncogene. 2014;33(37):4613. https://doi.org/10.1038/onc.2014.66 PMid:24662828

21. Wang $A$, Zhang $\mathrm{W}$, Jin $\mathrm{M}$, Zhang J, Li S, Tong $\mathrm{F}$, et al. Differential expression of EBV proteins LMP-1 and BHFR1 in EBV-associated gastric and nasopharyngeal cancer tissues. Mol Med Rep. 2016;13(5):4151-8. https://doi.org/10.3892/ mmr.2016.5087

22. Borthakur P, Kataki K, Keppen C, Khamo V, Medhi S, Deka M Expression of epstein barr virus encoded EBNA1 and LMP-1 oncoproteins in nasopharyngeal carcinomas from Northeast India. Asian Pac J Cancer Prev. 2016;17(7):3411-6. PMid:27509984

23. Rosales-Pérez S, Cano-Valdez AM, Flores-Balcázar $\mathrm{CH}$ Guedea-Edo F, Lino-Silva LS, Lozano-Borbalas A, et al. Expression of epstein-barr virus-encoded latent membrane protein (LMP-1), p16 and p53 proteins in nonendemic nasopharyngeal carcinoma (NPC): A clinicopathological study. Arch Med Res. 2014;45(3):229-36. https://doi.org/10.1016/j. arcmed.2014.02.002

PMid:24606815

24. Tabyaoui I, Serhier Z, Sahraoui S, Sayd S, Cadi R, Bennani O, et al. Immunohistochemical expression of latent membrane protein 1 (LMP-1) and p53 in nasopharyngeal carcinoma: Moroccan experience. Afr Health Sci. 2013;13(3):710-7. https:// doi.org/10.4314/ahs.v13i3.27

PMid:24250311

25. Kurnianda J, Hardianti MS, Harijadi TH, Purwanto I, Haryana SM, Tjokronagoro M. Elevation of vascular endothelial growth factor in Indonesian advanced stage nasopharyngeal carcinoma. Kobe J Med Sci. 2009;55(2):E36-44. PMid:20847590

26. Krishna SM, James S, Balaram P. Expression of VEGF as prognosticator in primary nasopharyngeal cancer and its 
relation to EBV status. Virus Res. 2006;115(1):85-90. https:// doi.org/10.1016/j.virusres.2005.07.010

PMid:16139912

27. Pan J, Tang T, Xu L, Lu JJ, Lin S, Qiu S, et al. Prognostic significance of expression of cyclooxygenase-2, vascular endothelial growth factor, and epidermal growth factor receptor in nasopharyngeal carcinoma. Head Neck. 2013;35(9):1238-47. https://doi.org/10.1002/hed.23116

PMid:22972415

28. Xinhua $X$, Guoqing H, Song L, Feng X, Daojun L, Delan D, et al. Expression of cyclooxygenase-2 in nasopharyngeal carcinoma and its relation to angiogenesis and prognosis. Chin German J Clin Oncol. 2006;5(2):104-7.

29. Sha D, He YJ. Expression and clinical significance of VEGF and its receptors Flt-1 and KDR in nasopharyngeal carcinoma. Ai Zheng. 2006;25(2):229-34.
PMid:16480593

30. Segawa $Y$, Oda $Y$, Yamamoto $H$, Shiratsuchi $H$, Hirakawa $N$, Komune S, et al. Close correlation between CXCR4 and VEGF expression and their prognostic implications in nasopharyngeal carcinoma. Oncol Rep. 2009;21(5):1197-202. https://doi. org/10.3892/or_00000341

PMid: 19360294

31. Paydas S, Ergin M, Erdogan S, Seydaoglu G. Prognostic significance of EBV-LMP-1 and VEGF-A expressions in nonhodgkin's lymphomas. Leuk Res. 2008;32(9):1424-30. https:// doi.org/10.1016/j.leukres.2008.01.008

32. Xu S, Bai J, Zhuan Z, Li B, Zhang Z, Wu X, et al. EBV-LMP-1 is involved in vasculogenic mimicry formation via VEGFA/ VEGFR1 signaling in nasopharyngeal carcinoma. Oncol Rep. 2018;40(1):377-84. https://doi.org/10.3892/or.2018.6414 PMid:29749553 